\title{
Patient Drug Information Leaflets for Risk/Benefit Communication
}

\section{Michiko Yamamoto*}

Education Center for Clinical Pharmacy Practice, Showa Pharmaceutical University, Japan

\section{Why is it Necessary for Patients to have the Drug's Information?}

The patient is an end user of medicine. Patient Drug Information Leaflets are usually provided for patients in many countries when they are on medication. However, why is providing the information of medicines so important for patients?

Firstly, patients have a right to receive good medical treatment, and in order to do so they need to know the medicines they are taking. Second, it is important for healthcare professionals and the patients to share this essential information in order to make the right decision for the patient. Finally and most importantly, it is to maximize the benefits of the medication as well as to minimize the risk associated with them. In other words, it is critical for Risk Minimization by making an early detection and preventing the progression of the disease.

\section{Patient's Rights and the Shared Decision Making}

Every patient wishes for drug information of good quality in medical treatment, and has the right to get it. Historically, the relationship between patients and healthcare professionals used to be paternalistic. However, changes are being seen in which informed consent is required and shared decision making is taken into account. Shared Decision Making is a collaborative process that allows patients and their healthcare professionals to make informed health care decisions together $[1,2]$. This takes into account the scientific evidences available as well as the patient's values and preferences.

The word, compliance, has been used to describe the degree to which a patient correctly follows the medical advice of their healthcare professionals on the drug administration methods. However, though it does not change the meaning of taking medicines, the word, adherence (with respects to the patient's decision) or concordance (in which patients and healthcare professionals reach to a mutual agreement after the discussion) have been used more frequently in time [3-5].

Concordance is a process of prescription and the use of drugs based on partnership agreement. In 1996, a subset of shared decision making, the concept of concordance was introduced by the Medicines Partnership Group established in UK. The following issues are considered to be important in concordance;

-Patients have enough knowledge to participate as partners.

-Healthcare professionals are prepared for partnership

-Prescribing consultations involve patients as partners

-Patients are supportive in taking medicines

It is desirable that a model for therapeutic decision making should use evidence but acknowledge the importance of patient factors and clinical expertise [5].

In any case, it is required that a doctor and a patient must form a mutual partnership and emphasize on the process of decision making. The information of medicines as a reliable source allows such decision to become indispensable for the patient. It is fundamental that patients understand the importance of taking the right medicines via the proper method. Moreover, it is absolutely necessary to improve not only on the compliances but on the therapeutic effects as well. Good information helps patients to participate fully in concordant decision-making about the medicines being prescribed for or recommended to them by their healthcare professionals.

\section{Risk Minimization}

Since the dissemination of information pertaining to the risk of medication such as the adverse effects of drugs, possesses a potential impact to public health, special attention has to be put into patient communication to reduce such risk. Risk Management Plan (RMP) has been implemented for safety securement of medicines since 2012 in Japan [6].

As one of the usual risk minimization activities, pharmaceutical companies were required to develop Drug Guides for patients where information regarding the active substances found in newly developed drugs can be obtained in concordance with the RMP scheme. This is exactly the same as Medication Guides which is a component of Risk Evaluation and Mitigation Strategy (REMS) in the US's FDA [7]. European Medicines Agency (EMA) also requires the Package Leaflets as a component of RMP since 2009.

Authorized medicine leaflets for patients compared among EU, US and Japan is shown in Table 1.

\section{Evidence and the User Test for Quality of the Information for Patients}

To provide the drug information for patients, a framework is needed in which the quality of the information is secured. It is important for a patient to be able to find the necessary information immediately without any difficulties understanding the information provided. To reflect on the patient's opinion and viewpoints, a scheme is required where the patients are directly involved and it is necessary to show whether an opinion was reflected as evidence.

This is where the user test comes in as a handy information evaluation method. Through performing the user test on each drug, suitability of the safety message description on the leaflet can be verified on how the information can be delivered as well as what kind of information and evidence are needed for the securement of the patient's safety. The user test of Patient Leaflet (PL) was required in 2005 at the EU to secure the quality of the information and at the same time to ensure that the patients and consumers could understand the information given [8]. Accessibility to information, readability and

*Corresponding author: Michiko Yamamoto, Education Center for Clinical Pharmacy Practice, Showa Pharmaceutical University, Tokyo, Japan, Tel: +81-42-721-1511; E-mail: m-yamamoto@ac.shoyaku.ac.jp

Received February 02, 2015; Accepted February 02, 2015; Published February 07, 2015

Citation: Yamamoto M (2015) Patient Drug Information Leaflets for Risk/Benefit Communication. J Pharmacovigilance 3: e132. doi:10.4172/2329-6887.1000e132

Copyright: @ 2015 Yamamoto M. This is an open-access article distributed under the terms of the Creative Commons Attribution License, which permits unrestricted use, distribution, and reproduction in any medium, provided the original author and source are credited. 
Citation: Yamamoto M (2015) Patient Drug Information Leaflets for Risk/Benefit Communication. J Pharmacovigilance 3: e132. doi: $10.4172 / 2329-6887.1000 \mathrm{e} 132$

Page 2 of 2

\begin{tabular}{|c|c|c|c|}
\hline Area/Countries (Regulatory Agency) & $\begin{array}{l}\text { 1.EU (EMA: European Medicines Agency) } \\
\text { 2.UK (MHRA: Medicines and Healthcare } \\
\text { products Regulatory Agency) }\end{array}$ & $\begin{array}{l}\text { USA (FDA: Food and Drug } \\
\text { Administration) }\end{array}$ & $\begin{array}{l}\text { Japan (MHLW: Ministry of Health Labour } \\
\text { and Welfare) }\end{array}$ \\
\hline Leaflet name & $\begin{array}{l}\text { 1.Package Leaflets (PILs) } \\
\text { 2.Patient Information Leaflets(PILs) }\end{array}$ & Medication Guides & Drug Guide for Patients \\
\hline Objective & $\begin{array}{l}\text { - Help patients participate fully in concordant } \\
\text { decision-making } \\
\text { - Facilitate safe use of the medicine }\end{array}$ & & Objective \\
\hline Beginning period & $\begin{array}{l}\text { 1.EMA:2001 (Article } 65 \\
\text { of Directive 2001/83/EC of the European } \\
\text { Parliament and Council) } \\
\text { 2.UK:1999 (Best } \\
\begin{array}{l}\text { practice guidance on patient information } \\
\text { leaflets issued by MHRA) }\end{array}\end{array}$ & $\begin{array}{l}1998 \\
\text { (Department of Health and Human } \\
\text { Services. Prescription Drug Product }\end{array}$ & Beginning period \\
\hline Risk Management Plan (RMP) & RMP components since 2009 & $\begin{array}{l}\text { Risk Evaluation and Mitigation Strategy } \\
\text { (REMS) components since } 2010\end{array}$ & RMP components since 2012 \\
\hline $\begin{array}{l}\text { Medicines targeted or conditions to } \\
\text { develop the leaflets }\end{array}$ & All medicines & $\begin{array}{l}\text { When the Agency determines that: } \\
\text { - certain information is necessary to } \\
\text { prevent serious adverse effects } \\
\text { - patient decision-making should be } \\
\text { informed by information about a known } \\
\text { serious side effect with a product, or } \\
\text { - patient adherence to directions for } \\
\text { the use of a product is essential to its } \\
\text { effectiveness. }\end{array}$ & $\begin{array}{l}\text { Drug Guide for Patients are requested to } \\
\text { consolidate for following medicines: } \\
\text { - In which a Warning Box is set up in a } \\
\text { Package Insert. } \\
\text { - on which doctors or pharmacists } \\
\text { are asked to explain to the patients } \\
\text { to prevent possible serious adverse } \\
\text { reactions (SAE) and SAE described in } \\
\text { a Package Insert. } \\
\text { - in which information is given to patients } \\
\text { for their proper use in particular. }\end{array}$ \\
\hline Provided style & $\begin{array}{l}\text { 1.Printed materials (package insert) } \\
\text { 2.Web (EMA,MHRA,eMC) }\end{array}$ & $\begin{array}{l}\text { 1.Paper handouts } \\
\text { 2.Web(FDA) }\end{array}$ & $\begin{array}{l}\text { Web (PMDA: Pharmaceuticals and } \\
\text { Medical Devices Agency) }\end{array}$ \\
\hline Literacy levels & equivalent to 11 years old & equivalent to 11 years old & equivalent to 14 years old \\
\hline Table of contents & Yes & No & No \\
\hline Description of Adverse reactions & $\begin{array}{l}\text { Serious side effects and Common side } \\
\text { effects (listed by seriousness and then by } \\
\text { frequency.) }\end{array}$ & $\begin{array}{l}\text { Serious side effects and Common } \\
\text { side effects (Not required to describe } \\
\text { occurrence frequency) }\end{array}$ & $\begin{array}{l}\text { Serious adverse reactions (Not required } \\
\text { to describe occurrence frequency }\end{array}$ \\
\hline
\end{tabular}

Table 1: Authorized medicine leaflets for patients compared among EU, US and Japan.

understandability are inspected by the test whereby it is required to take patient's opinion and to be shown as evidence [9-12]. This user test also functions as a diagnostic test to improve the delivery of medicine information. Such delivery includes pamphlets, Patient Leaflets as well as web information. In this user test, it is important that the test be conducted as close as to an actual life event to increase the accuracy of the results obtained.

In order to understand how the test participants deal with information regarding to their prescribed medicines, it is necessary to dwell and understand how these participants interpret the information as well as establishing a questionnaire to determine whether or not these participants are able to decipher specific parts from the information [13].

Due to the safety securement of the patients as another main aim of the user test, it is important to discuss and plan on how the importance of safety messages can be incorporated into the questionnaire. According to Dr. Baruch Fischhoff, "if its message is not understood by the recipient, you should conclude that the responsibility is in the oneself informer side and it is not in the recipient side". I also think it is important to keep inspecting that such basic issue is informed in the information for the patients [14].

In terms of readability, accessibility and understandability of drug information for patients, we need to involve the public on how its quality should be assured and easily comprehensible for patients to make effective use of "Drug Guides for Patients" in the future in Japan.

\section{References}

1. Whitney SN (2003) A new model of medical decisions: exploring the limits of shared decision making. Med Decis Making 23: 275-280.
2. McNutt RA (2004) Shared medical decision making: problems, process, progress. JAMA 292: 2516-2518.

3. Concordance, adherence and compliance in medicine taking. Report for the National Co-ordinating Centre for NHS Service Delivery and Organisation R $\& D(N C C S D O)$

4. Aronson JK (2007) Compliance, concordance, adherence. Br J Clin Pharmaco 63: 383-384.

5. Haynes RB, Sackett DL, Taylor DW (1979) Compliance in health-care Baltimore. MD: John Hopkins University Press

6. Guidance for Risk Management Plan issued by MHLWin Japan

7. Approved Risk Evaluation and Mitigation Strategies (REMS) at US FDA

8. Guideline on the Readability of the Labelling and Package leaflet of Medicinal Products for Human Use.

9. Best Practice Guidance on the Labelling and Packaging of Medicine

10. Guidance on the user testing of patient information leaflets published by MHRA ,2005

11. Further guidance on designing patient information leaflets and how to achieve success in user testing published by MHRA in UK, 2007

12. Europian Commission Guideline on the Readability of the Labelling and Package Leaflet of Medicinal Products for Human Use Revision, 2011

13. Sless D, Wiseman R (2006) Writing about medicines for people Usability guidelines for consumer medicine information. Communication institute of Australia, Third Edition.

14. Fischhoff B, Noel T, Brewer, Downs J S (2011) Communicating Risk and benefits: An Evidence -Based User's Guide. 